\title{
Capacidades tecnológicas e suas implicações para performance técnica: a experiência de duas empresas de telefonia celular no Brasil
}

\author{
Rodrigo C. Araujo*
}

\section{Resumo}

Este artigo examina as implicações da acumulação de capacidades tecnológicas para 0 aprimoramento da performance técnica em duas empresas de telefonia celular no Brasil. 0 estudo adotou uma perspectiva abrangente para capacidade tecnológica que vai além dos seus elementos convencionais, tais como sistemas técnico-físicos e capital humano, para captar a dimensão organizacional da capacidade tecnológica. Neste artigo examina-se atividade tecnológica - aquilo que a empresa é capaz de fazer tecnologicamente de maneira independente - como expressão da capacidade tecnológica. Para operacionalizar tal perspectiva, faz-se uso de uma métrica sistemática, compreensiva e calibrada para medir capacidade tecnológica na indústria de telefonia celular. A métrica identifica tipos e níveis de capacidades para três funções tecnológicas: (i) gestão de projetos; (ii) serviços; e (iii) equipamentos. 0 artigo faz uso de vários indicadores de performance técnica em nível das empresas estudadas (1993-200). Este estudo baseia-se em evidências empíricas de primeira-mão coletadas por meio de múltiplas técnicas durante extensivo trabalho de campo. A maneira e a velocidade de acumulação de capacidade tecnológica jogaram um papel crucial no incremento da performance técnica das empresas. 0 estudo sugere que, em um ambiente de competição acirrada, onde a qualidade dos serviços ao usuário é uma condição crucial para sua permanência no mercado, as empresas são obrigadas a desenvolver capacidades tecnológica a uma velocidade rápida para garantirem a melhoria de sua performance técnica - e a sua própria sobrevivência.

Palavras-chave: Capacidades tecnológicas; performance técnica; empresas de telefonia celular

\begin{abstract}
This article examines the implications of technological capability accumulation for technical performance improvement in two mobile phone companies in Brazil. The article adopts a comprehensive perspective on technological capability that goes beyond conventional elements - such as techno-physical systems and human capital - to capture the organizational dimension of technological capability. This article examines the technological activity - i.e. what the firm can do technologically on its onw - as an expression of technological capability. In order to operationalize such approach, this article makes use of a systematic, comprehensive and tailored framework for measuring technological capability accumulation in the mobile phone industry. The framework identifies types and levels of capabilities for three technological functions: (i) project management; (ii) services; and (iii) equipment. This article makes use of various technical performance indicators at the level of the case-study-companies (1993-2000). The article draws on first-hand empirical evidence collected through different data-gathering techniques during extensive fieldwork. The manner and speed of technological capability accumulation have played an important role in improving the technical performance of the case-study companies. The study suggests that an environment marked by competitive pressures and users' highquality requirements stimulates firms to speed up their technological capability-accumulation process in order to improve their technical performance.
\end{abstract}

Key-words: Technological capability; technical performance; mobile phone industry.

* Diretor de operação e manutenção de Rede da Claro S.A. E- mail: rodrigo.araujo@ claro.com.br. Endereço: Av. Voluntários da Pátria, 143, 30. andar. Rio de Janeiro-RJ Artigo recebido em novembro de 2004 e aceito para publicação em março de 2005. 


\section{Introdução}

No início da década de 1980, as atividades tecnológicas em empresas industriais passaram a ser consideradas numa perspectiva evolutiva (ROSENBERG, 1982; NELSON \& WINTER, 1982; WINTER, 1988; NELSON, 1991). Tal perspectiva baseava-se nos estudos de March \& Simon, (1958), sobre 'comportamento rotinizado' nas organizações, de Simon (1959, 1961), sobre 'racionalidade limitada', e de Penrose (1959), que já consideravam as capacidades específicas à firma como fator chave para a sua performance competitiva. Sob essa perspectiva, as empresas são vistas como organizações dinâmicas que sabem como fazer as coisas. A empresa é um repositório de saber produtivo que a distingue inclusive de empresas similares do mesmo setor industrial (WINTER, 1988). Essa perspectiva evolutiva é capaz de explicar a diversidade encontrada quando se investigam as atividades tecnológicas das empresas, mesmo quando elas evoluem sob as mesmas condições econômicas (NELSON, 1991).

Associada a essa perspectiva está a idéia da "permanente existência de assimetrias entre as empresas no que se refere às tecnologias de processos e à qualidade da produção. Ou seja, em geral as empresas podem ser classificadas como 'melhores' ou 'piores' conforme o nível de sua tecnologias" (DOSI, 1985, p. 19). Tais diferenças também estão ligadas às principais características do processo de inovação dentro da empresa, o qual é 'variável' (NELSON, 1991) e 'dependente da trajetória' (DOSI, 1988; PAVITT, 1988; TEECE, 1988). Além disso, os conhecimentos de que se vale uma empresa, sob a forma de competências, são específicos à mesma, ou seja, estão embutidos em suas "rotinas". Tais rotinas, segundo se afirma, influenciam diretamente o desempenho eficaz da organização (NELSON \& WINTER, 1982).

No começo dos anos 1990, Teece et al. (1990) aprimoraram o modelo explanatório das capacidades tecnológicas em empresas. Partindo da abordagem baseada em recursos, porém indo mais além, o modelo focaliza os mecanismos pelos quais as empresas acumulam novas competências. Nessa perspectiva, a vantagem competitiva sustentável tem sua origem nas competências, capacidades ou ativos estratégicos da empresa (PRAHALAD \& HAMEL, 1990; PAVITT, 1991; DODGSON, 1993; MALERBA \& ORSENIGO, 1993). Deu-se grande destaque aos recursos da empresa e à sua habilidade de desenvolver capacidades específicas (por exemplo, PRAHALAD \& HAMEL, 1990).

Para Pavitt (1991), as capacidades específicas à empresa explicam por que as empresas são diferentes, por que elas mudam com o tempo, e se elas são capazes ou não de continuar competitivas. Posteriormente, o modelo das 'capacidades dinâmicas' (TEECE \& PISANO, 1994) veio explicar as diferenças entre as empresas no tocante à vantagem competitiva. Tomando por base alguns desses enfoques, Leonard-Barton (1992, 1995) formulou o modelo da "capacidade básica". Todos esses modelos procuram mostrar como as empresas tornamse mais competitivas fortalecendo as capacidades já existentes, mas parecem desconsiderar como tais capacidades foram primeiramente criadas.

Essa perspectiva influenciou a emergência de estudos sobre as implicações das capacidades tecnológicas para o aprimoramento da performance técnico-econômica de empresas de países em desenvolvimento - ou de industrialização tardia - já nos anos 1960 (ver, por exemplo, HOLLANDER, 1965). De maneira sistemática, estudos preocupados com essas questões, em empresas de países em desenvolvimento, emergiram em meados dos anos 1970 a partir da América Latina (ver, por exemplo, KATZ, 1976; DAHLMAN \& FONSECA, 1978 e vários outros).

A partir do início dos anos 1990s, novos estudos emergiram para examinar essas questões em empresas de maneira compreensiva, ou seja, com forte ênfase na dimensão organizacional da capacidade tecnológica. Por exemplo, Piccinini (1993) examinou a relação entre capacidade tecnológica e desempenho energético em duas empresas de aço no Brasil. O estudo constatou que o melhor desempenho energético foi obtido pela empresa que dinamicamente acumulou capacidade tecnológica utilizando-se dos fluxos de conhecimentos interativos. $\mathrm{O}$ autor não pesquisou, porém, a trajetória de acumulação de capacidade tecnológica nas duas empresas. 
Adotando uma perspectiva ainda mais ampla, Tremblay (1994) tomou uma amostra de fábricas de papel na Índia e no Canadá e fez uma análise comparativa das dimensões organizacionais da capacidade tecnológica associadas à performance ao longo do tempo. Entre essas dimensões incluíam-se: motivação e compromisso com a mudança; cúpula; relações cooperativas; processo de tomada de decisões; controle e canal de comunicação; fluxo de informações; interação/influência; tipo de hierarquia; inércia organizacional e atitude gerencial. O estudo não encontrou correlação positiva entre aumento da produtividade e capacidade tecnológica em sentido restrito, isto é, incorporada apenas em um grupo de indivíduos e não nos sistemas organizacionais. Por outro lado, constatou uma ligação explícita entre capacidade tecnológica incorporada nos sistemas organizacionais e aumento da produtividade das empresas. $\mathrm{O}$ trabalho de Tremblay contribuiu para suprir as limitações de estudos anteriores que procuraram explicar as diferenças internacionais de produtividade no contexto recém-industrializado com base em uma composição restrita de capacidade tecnológica (por exemplo, PACK, 1987). Contudo, Tremblay não reconstituiu a trajetória de acumulação de capacidade tecnológica seguida por aquelas empresas, nem examinou os processos de aprendizagem que lhes são subjacentes.

Preocupado em gerar explicações para diferenças entre empresas, no mesmo setor industrial no contexto de países em desenvolvimento, em termos de performance técnico-econômica, Figueiredo (2001) examinou o papel do modo e da velocidade da acumulação de capacidades tecnológicas, em nível de empresas, e dos processos subjacentes de aprendizagem, nessas diferenças entre empresas. No Brasil, estudos recentes têm examinado a relação entre capacidades tecnológicas e performance técnico-econômica na indústria de móveis (p.ex. BEN \& FIGUEIREDO, 2005, nesta edição) e na indústria de telefonia fixa (ver BELINGHINI \& FIGUEIREDO, 2005), embora empresas de telefonia fixa ainda não tenham sido estudadas sob essa perspectiva.

Este artigo examina o papel das capacidades no aprimoramento da performance competitiva em nível de empresa, na indústria de telefonia celular, com base em um estudo de caso individual. Especificamente, este artigo enfoca essas duas questões em duas empresas de telefonia celular no Brasil (de 1993 a 2000), conforme esquematizado na Figura 1 a seguir.

Figura 1. Foco deste artigo

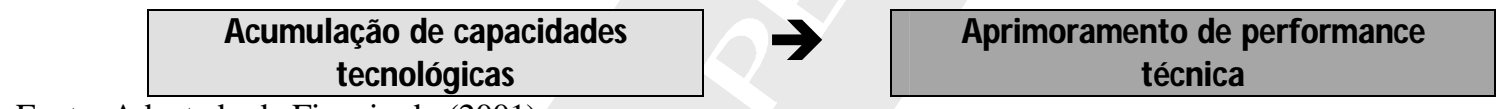

Fonte: Adaptado de Figueiredo (2001)

Reconhecemos que, além das capacidades tecnológicas internas, outras variáveis podem afetar, indiretamente, performance técnico-econômica, como por exemplo, os processos subjacentes de aprendizagem tecnológica e outros fatores intra-organizacionais, tais como valores, normas e disputas de poder. Outros variáveis como as macro-econômicas ou mesmo setoriais (incentivos à exportação, políticas setoriais) e crises externas (como a energética) podem gerar efeitos diretos sobre a performance de empresas. Porém, esses fatores estão além do escopo deste artigo.

Este artigo está estruturado como segue. A Seção 2 apresenta o contexto empírico do estudo subjacente a este artigo. O modelo para exame de capacidade tecnológica na indústria de telefônica celular é apresentado na Seção 3. O desenho e métodos do estudo são apresentados na Seção 4. As Seções 5 e 6 apresentam as evidências empíricas do estudo, ou seja, as capacidades tecnológicas e suas implicações para indicadores de performance técnica. Finalmente a Seção 7 discute as conclusões e implicações do artigo. Por razão de confidencialidade, os nomes das empresas estudadas não são revelados neste artigo. As empresas são tratadas aqui simplesmente por empresas $\mathrm{X}$ e $\mathrm{Y}$. 


\section{Contexto empírico do estudo}

\subsection{A indústria de telecomunicações no Brasil: breve nota de sua evolução recente}

Do início da década de 1960 ao final da década de 1990, o mercado brasileiro de telecomunicações passou por diversas mudanças, principalmente no que diz respeito às atribuições do governo e de empresas operadoras quanto ao regime dos serviços de telecomunicações. $\mathrm{O}$ ritmo dessas mudanças tem intensificaram-se durante a década 1990, principalmente após o início do processo de privatização, ocorrido a partir de 1997. O processo de privatização estimulou a competição entre empresas prestadoras dos serviços de telecomunicações, obrigandoas a um posicionamento muito mais agressivo no mercado e uma busca de melhoria de suas estratégias empresariais.

Historicamente, por força da Constituição de 1946, cabia à União, aos estados e aos municípios a exploração, de acordo com seu âmbito, dos serviços de telecomunicações, no Brasil. Assim sendo, o serviço de telecomunicações e, conseqüentemente, as suas tarifas encontravam-se descentralizados. Naquela época, constituído basicamente de empresas de pequeno e médio porte, o sistema brasileiro de telecomunicações apresentava um número de empresas que girava em torno de $1.200^{1}$.

Apesar do grande número de empresas instaladas - e como não havia coordenação entre elas - surgiram algumas discrepâncias quanto às formas de prestação do serviço. Além de precários, havia uma nítida concentração dos serviços oferecidos - eles eram prestados principalmente nas capitais e explorados majoritariamente, nessas cidades, por uma única empresa: a Companhia Telefônica Brasileira (CTB) de capital canadense, que detinha cerca de $60 \%$ do mercado brasileiro. De forma análoga, os serviços de longa distância também eram precários, com operação manual, com várias horas de espera para que as chamadas realizadas fossem completadas ${ }^{2}$. Assim como os serviços telefônicos e telegráficos internacionais, os serviços interurbanos interligavam apenas algumas capitais e possuíam capacidade muito inferior a sua demanda.

Diante desse quadro, no intuito de apresentar soluções para a situação precária do setor de telecomunicações, o Governo Federal e o Congresso Nacional editaram, em Agosto de 1962, o Código Brasileiro de Telecomunicações. Seguem dois dos principais pontos abordados pelo Código:

- os serviços de telégrafos, radiocomunicações e telefonia interestadual ficariam sob jurisdição da União;

- o Poder Executivo está autorizado a constituir empresa pública para explorar industrialmente a infraestrutura para prestação de serviços, o que deu origem ao Sistema Nacional de Telecomunicações (SNT).

Três anos após a criação do referido Código, surgia a Empresa Brasileira de Telecomunicações (EMBRATEL), em 16 de setembro de 1965. Foi criada com o objetivo de interligar todas as capitais e principais cidades do Brasil e ainda o de assumir a exploração dos serviços internacionais de telefonia à medida que os prazos de concessão das antigas empresas operadoras se expiravam.

Em fevereiro de 1967, através de decreto-lei, que foi posteriormente consolidado pela Constituição promulgada no mesmo ano, concentrou-se na União o poder de outorga de concessões para prestação de serviços públicos de telecomunicações. Essa diretriz manteve-se até a Constituição de 1988, que determinou que tais serviços somente poderiam ser prestados pela União - diretamente ou através de concessões a empresas sob controle acionário estatal.

As ações iniciais contribuíram significativamente para a melhoria do sistema de telefonia interurbano e internacional. Em função disso, o Governo Federal, em 1971, começou o processo de criação de uma entidade pública cujo objetivo seria planejar e coordenar as telecomunicações em âmbito nacional. Surgia assim a idéia da criação da Telecomunicações Brasileiras (TELEBRÁS), que se concretizou em 11 de julho de 1972. Logo

\footnotetext{
${ }^{1}$ Fonte: Página web - http://www.mc.gov.br/Biblioteca/Publicações/avisos/Sumário_exec_l.html

${ }^{2}$ Entrevista com ex-funcionário da Embratel
} 
após a sua criação, a TELEBRÁS iniciou o processo de consolidação do sistema de telecomunicações nacional. No seu período inicial, basicamente, atuou adquirindo e absorvendo as empresas já existentes responsáveis pela prestação dos serviços de telefonia. Tal ação tinha o objetivo de consolidar as então 900 operadoras independentes, transformando-as em operadoras de âmbito estadual sob direção da própria TELEBRÁ ${ }^{3}$.

A unificação foi consolidada em 1974, quando a TELEBRÁS foi designada 'concessionária geral' para exploração dos serviços públicos de telecomunicações. Nesse ponto, o governo brasileiro passou a adotar políticas nacionais de desenvolvimento da infra-estrutura de telecomunicações. Ressalta-se nesse momento, a criação do Centro de Pesquisa e Desenvolvimento (CPqD), em Campinas. Ou seja, o modelo adotado também seria baseado no monopólio estatal. Existiam três grandes objetivos ligados à estratégia desse modelo:

- garantir o desenvolvimento de fornecimento interno de equipamentos que deveriam ser gradualmente nacionalizados;

- garantir o desenvolvimento de indústrias sob controle brasileiro; e,

- por último, reduzir a dependência do setor quanto à tecnologia importada.

Com a criação da TELEBRÁS e a adoção de políticas de incentivo para o desenvolvimento da infra-estrutura de telecomunicações instalada no Brasil, a partir da década de 1970, verificou-se no Brasil um significativo aumento de capacidade instalada. A planta de terminais telefônicos do Sistema TELEBRÁS cresceu, entre 1974 e 1994, cerca de 500\%, atendendo mais de 20.000 localidades $^{4}$. O modelo adotado pelo governo e suas estratégias alcançaram grande parte de seus objetivos. Porém, apesar do elevado crescimento da infra-estrutura instalada, a demanda por serviços de telecomunicações cresceu a taxas ainda maiores. No mesmo período, o tráfego cursado no serviço local cresceu mais de $1.200 \%$ e, no serviço interurbano, $1.800 \%{ }^{5}$.

A partir dessas altas taxas de crescimento, observa-se que a demanda pelo serviço de telefonia dificilmente teria condições de ser atendida pelo Sistema TELEBRÁS - com o agravante de os índices de tráfego não levarem em consideração a demanda que seria gerada pela parcela não atendida por serviços de telefonia. Em 1996, a demanda por terminais girava entre 18 e 25 milhões. Na mesma época, os terminais existentes atendiam apenas cerca de 14,5 milhões de usuários ${ }^{6}$.

Além da diferença entre terminais instalados e sua demanda, existia outro problema a ser observado: $80 \%$ dos terminais instalados atendiam a famílias de classes A, B e apenas $2 \%$ das propriedades rurais contavam com serviço telefônico; também havia um número reduzido de telefones públicos ${ }^{7}$. Tal situação refletia a incapacidade do Sistema TELEBRÁS em garantir o crescimento adequado da planta, a ponto de prestar o serviço capaz de atender a todas as camadas da sociedade.

Várias razões podem ser apontadas para que isso ocorresse: inadequada capacidade das empresas para manter o nível de investimentos necessários para suprir as necessidades de crescimento do setor; competição predatória entre as empresas locais e a Embratel $^{8}$; restrições à gestão empresarial das empresas estatais, que se equiparavam a empresas de administração pública e, portanto, eram excessivamente limitadas em sua flexibilidade técnica; por fim, a acomodação resultante do monopólio, que não impunha a necessidade de conquistar, satisfazer e manter clientes.

\footnotetext{
${ }^{3}$ Fonte: Página web - http://www.mc.gov.br/Biblioteca/Publicações/avisos/Sumário_exec_I.html

${ }^{4}$ Fonte: Página web - http://www.mc.gov.br/Biblioteca/Publicações/avisos/Sumário_exec_l.html

${ }^{5}$ Fonte: Página web - http://www.mc.gov.br/Biblioteca/Publicações/avisos/Sumário_exec_l.html

${ }^{6}$ Fonte: Página web - http://www.mc.gov.br/Biblioteca/Publicações/avisos/Sumário_exec_l.html

${ }^{7}$ Entrevista com ex-funcionário da Embratel

${ }^{8}$ Entrevista com ex-funcionário da Embratel
} 
Esse quadro perdurou até 1996, enquanto os serviços de telecomunicações no Brasil eram explorados por uma empresa "holding", a TELEBRÁS; por uma operadora de serviços de longa distância, de dados e de telex, a EMBRATEL; por 27 empresas com área de atuação estadual e/ou local e quatro empresas independentes: CRT (Rio Grande do Sul); SERCOMTEL (Londrina, PR); CETERP (Ribeirão Preto, SP); e CTBC (Uberlândia, no Triângulo Mineiro, MG, nordeste de São Paulo, sul de Goiás e no sudeste do Mato Grosso do Sul). Sob eessa configuração, o sistema TELEBRÁS era responsável por cerca de noventa por cento da planta instalada de telecomunicações no Brasil ${ }^{9}$.

Observando o quadro existente no setor, era clara a necessidade da implementação de novas mudanças. Estas foram introduzidas por meio de um programa do Governo Federal iniciado em 1994 que envolvia as seguintes diretrizes:

- Assegurar os direitos dos usuários dos serviços de telecomunicações;

- Incentivar o aumento de capitais privados, nacionais e estrangeiros nas atividades relacionadas ao setor;

- Promover a transição para um novo modelo no setor de telecomunicações, preservando o interesse público.

As medidas do Governo Federal culminaram com a criação de regiões de atuação para as empresas prestadoras dos serviços de telecomunicações, com a privatização das operadoras já existentes e com o surgimento de novas empresas. Tais mudanças introduziram a competição no mercado de prestação de serviços de telefonia e de transmissão de dados.

Dessa forma, os mercados de telefonia fixa, móvel e transmissão de dados passaram de um monopólio estatal para duopólios privados para cada tipo de serviço (longa distância, telefonia fixa local, serviço móvel celular, etc), atuando em regiões específicas. Em cada região de atuação, passaram a existir duas empresas concorrentes, prestando o mesmo serviço, ou seja, duas operadoras de telefonia fixa, duas telefonia celular e duas de longa distância. As regiões especificadas pela ANATEL foram as seguintes:

- Telefonia Fixa. Três regiões com a seguinte abrangência:

- Estado de São Paulo;

- Região Sudeste, exceto o estado de São Paulo, Região Nordeste e Região Norte, exceto os estados de Tocantins, Acre e Rondônia;

- Região Sul, Região Centro Oeste e os seguintes estados da Região Norte Tocantins, Acre e Rondônia, esses últimos localizados na Região Norte.

- Telefonia Móvel Celular. Dez regiões com a seguinte abrangência:

- Região 1: Área Metropolitana da Cidade de São Paulo;

- $\quad$ Região 2: Estado de São Paulo, excetuando-se a Região 1;

- Região 3: Estados do Rio de Janeiro e Espírito Santo;

- $\quad$ Região 4: Estado de Minas Gerais;

- Região 5: Estados de Santa Catarina e Paraná;

- $\quad$ Região 6: Estado do Rio Grande do Sul;

- Região 7: Distrito Federal e estados de Tocantins, Goiás, Mato Grosso, Mato Grosso do Sul, Rondônia e Acre;

- $\quad$ Região 8: Estados do Amazonas, Pará, Maranhão, Roraima e Amapá;

- Região 9: Estados de Bahia e Sergipe;

\footnotetext{
${ }^{9}$ Fonte: Página web - http://www.mc.gov.br/Biblioteca/Publicações/avisos/Sumário_exec_l.html
} 
- Região 10: Estados de Piauí, Ceará, Rio Grande do Norte, Paraíba, Pernambuco e Alagoas.

- Telefonia de longa distância. Atuando em todo o território nacional

As empresas em estudo neste artigo, a Empresa X e a Empresa $\mathrm{Y}$ atuavam, respectivamente, nas Regiões 4 e 7. É evidente a eficácia das medidas adotadas pelo Governo Federal. Após a privatização, o mercado de telecomunicações cresceu em ritmo acelerado. Semente em 1999 movimentou cerca de R 36 bilhões. Quando as empresas de telefonia fixa foram privatizadas, em julho de 1998, o número de terminais instalados era de cerca de 20 milhões. Após a privatização, em março de 2000, o número de acessos já era superior a 31 milhões, o que mostra o vertiginoso crescimento do setor ${ }^{10}$.

Especificamente, em relação à telefonia móvel, o número de acessos móveis, que era de cerca de 5 milhões em 1997, chegou a mais de 16 milhões em março de 2000. Vários fatores contribuíram para esse crescimento ${ }^{11}$ :

- Demanda por acessos móveis reprimida, principalmente em grandes centros;

- Demanda por telefonia fixa reprimida, o que fazia do celular uma solução para a falta de linhas fixas;

- Introdução da modalidade pré-pago, que possibilitou a oferta do serviço a camadas de menor poder aquisitivo;

- Desenvolvimento tecnológico, que possibilitou a redução de custos;

Espera-se que o crescimento do setor de telecomunicações continue acentuado e que, até 2006, venha a receber investimentos da ordem de $\mathrm{R} \$ 90$ bilhões, $\mathrm{R} \$ 52$ bilhões para telefonia fixa, e $\mathrm{R} \$ 38$ bilhões para telefonia móvel ${ }^{12}$.

O cenário apresentado mostra um setor em constante mudança e em pleno desenvolvimento. Neste setor, muitos aspectos ainda estão por ser definidos e ajustados às condições de mercado e de tecnologia. Essa condição de ajuste caracteriza o setor de telecomunicações como ainda em processo de industrialização, formado por empresas que ainda estão se instalando e firmando sua presença no mercado. Por estarem inseridas no contexto descrito, a Empresa X e a Empresa Y também sofreram mudanças ao longo do tempo. Nas subseções seguintes serão apresentados breves históricos sobre as duas empresas aqui estudadas.

\subsection{Breve nota sobre a empresa $X$}

Identificando a necessidade do mercado de telecomunicações local, a empresa $\mathrm{X}$, operadora de telefonia fixa iniciou, em 1992, um processo de licitação e contrato do projeto e implantação de uma rede capaz de prestar o serviço de telefonia móvel celular. Por fazer parte do sistema TELEBRÁS, a Empresa X seria a única empresa prestadora desse novo serviço, detendo assim o monopólio desse nicho de mercado na região. Com o objetivo de operar a nova rede celular, foi criada a Divisão Celular composta por três técnicos de comutação e três técnicos de campo. Essa divisão, ligada à estrutura do 'call center' do serviço celular, seria responsável pelas atividades de implantação e operação da nova rede.

À medida que o sistema celular expandia-se, a estrutura organizacional responsável pelos assuntos ligados à rede celular também ia sendo alterada. Assim, de um simples grupo de técnicos e engenheiros ainda subordinados à estrutura da rede fixa, já no final de 1993, foi criada uma gerência independente que cuidaria dos diversos processos relacionados à rede celular. Nela, haveria várias divisões responsáveis pelos mais variados processos como operação, manutenção, vendas, definição de produtos e atendimento ao cliente. Naquele momento, departamentos como financeiro, recursos humanos e planejamento, ainda estavam ligados à estrutura da rede fixa, prestando um serviço integrado para os dois sistemas.

\footnotetext{
${ }^{10}$ BNDES/FINAME/BANESPAR: Cadernos de Infra-estrutura - As Telecomunicações no Brasil (Jun/2000)

${ }^{11}$ Fonte: Página web - http://www.mc.gov.br/Biblioteca/Publicações/avisos/Sumário_exec_I.html

${ }^{12}$ Fonte: Página web - http://www.mc.gov.br/Biblioteca/Publicações/avisos/Sumário_exec_I.html
} 
A partir desse momento, a Empresa X passa a evoluir técnica e organizacionalmente até meados 1998, quando é privatizada e deixa de fazer parte do sistema TELEBRÁS. Nesse momento, tornou-se uma empresa privada, operando não mais em um mercado de monopólio mas sim de duopólio, tendo que concorrer no mercado com outra nova empresa. Passa a ser necessário, nesse momento, aplicar e desenvolver capacidades tecnológicas que efetivamente permitissem destacar-se no novo cenário a que estava sendo submetida.

Dessa forma, ao longo da história da Empresa X, podem-se destacar três marcos:

- A implantação do serviço iniciada em setembro de 1992;

- A criação da Superintendência de Telefonia Móvel Celular, posteriormente conhecida como Empresa X, em 1996;

- A privatização surgindo como empresa independente do sistema Telebrás, em 1998.

De final de 1996 a final de 2000, rede da Empresa X evoluiu significativamente, conforme especificado na Tabela 1.

Tabela 1: Evolução da Rede da Empresa X

\begin{tabular}{cccc}
\hline Item & $\mathbf{1 9 9 6}$ & $\mathbf{2 0 0 0}$ & Crescimento (\%) \\
\hline CCC & 8 & 10 & 25 \\
\hline ERB & 389 & 655 & 68 \\
\hline Assinantes & 248442 & 1242236 & 400 \\
\hline
\end{tabular}

Fonte: Relatórios de desempenho e análise de tráfego do SMC da rede da Empresa X - 1996 a 2000

\subsection{Breve nota sobre a empresa $Y$}

Em 1997, o Governo Brasileiro iniciou o processo de privatização do mercado de telecomunicações no Brasil. Foi assim implementado um novo modelo econômico para esse mercado, o de duopólio. Com o novo modelo adotado (duopólio), o governo acreditava ser possível atrair novos investidores e dar um novo ritmo ao crescimento para esta indústria. Em julho daquele ano, o Governo Federal definiria o processo de licitação para a área de operação denominada como Região 7 constituída pelos estados de Goiás, Tocantins, Mato Grosso, Mato Grosso do Sul, Rondônia, Acre e pelo Distrito Federal. A empresa ganhadora desse processo foi a Empresa Y. A partir daí, inicia-se o processo de construção da empresa. E, finalizadas as negociações iniciais, a Empresa Y deu início à implantação se sua rede de telefonia móvel digital. As atividades iniciaram-se no mês de setembro. Exatos dois meses depois, iniciava a operação de sua rede.

Em cada um dos estados constituintes da Região 7, como em todos os outros estados do país, já existia empresas de telefonia móvel celular operando na Banda A, pertencentes ao Sistema TELEBRAS. Essas empresas já possuíam suas redes de telecomunicações bastante desenvolvidas, fornecendo seus serviços nas mais diversas localidades, tanto em regiões de perímetro urbano quanto rural, apresentando, portanto, um nível de qualidade de cobertura muito bom.

Outro aspecto muito importante dessas empresas estava na sua base de assinantes já desenvolvida. Por volta de 1997, esses assinantes representavam a totalidade do mercado de telefonia celular. Em função do desafio de competir com uma empresa já estruturada, e das condições de aquisição de sua licença, que a obrigava iniciar suas operações em apenas cinco meses, o objetivo primordial da Empresa Y era o de implantar no menor período possível sua rede de telefonia móvel celular. E, a partir disso, estar capacitada para prestar o seu serviço e começar a desenvolver sua base de assinantes. Para suportar o tráfego gerado pelo crescimento do número de assinantes, a rede da Empresa Y cresceu, de início de 1998 ao final de 2000, conforme especificado na Tabela 2, abaixo. 
Tabela 2. Evolução da rede da empresa $Y$

\begin{tabular}{cccc}
\hline Item & $\mathbf{1 9 9 7}$ & $\mathbf{2 0 0 0}$ & Crescimento (\%) \\
\hline CCC & 2 & 8 & 300 \\
\hline ERB & 116 & 383 & 200 \\
\hline Assinantes & 15897 & 388437 & 2300 \\
\hline
\end{tabular}

\section{Modelo para exame da acumulação de capacidades tecnológicas nas empresas estudadas}

A trajetória de acumulação de capacidades tecnológicas nas duas empresas estudadas é examinada à luz do modelo (ou métrica) desenvolvido e aplicado em Figueiredo (2001). Essa métrica foi adaptada, calibrada e validada para empresas prestadoras de serviço móvel celular, conforme apresentada na Tabela 3. A acumulação de capacidades pode variar de níveis básicos (atividades de 'rotina') até níveis de elevado grau de complexidade (atividades 'inovadoras'). Na Tabela 3, a primeira coluna mostra os níveis de capacidade e as demais colunas, as funções tecnológicas estudadas (processo de produção, produto e equipamentos). Nas linhas estão dispostos os graus de dificuldade referentes a cada nível de competência, mostrando a respectiva descrição para cada função. As capacidades tecnológicas são expressas pelas atividades que a empresa é capaz de realizar, de maneira indenpendente.

\subsection{Capacidades tecnológicas em gestão de projetos}

Tais capacidades são necessárias para identificar, preparar e obter tecnologia que permita à empresa desempenhar atividades de projeto, implementação, definição de equipamentos, seleção de pessoal capacitado e aceitação de novos equipamentos e de expansões da planta existente. Além disso, essas capacidades estão ligadas à especificação dos custos de capital e ao dimensionamento de projetos, à definição do mix de produtos a serem lançados e à seleção de tecnologia a ser utilizada. Sob o título de capacidades relativas a gestão de projetos, existem duas funções tecnológicas relacionadas:

i. Decisão e controle sobre a planta: envolvem definições e escolhas relativas à evolução da planta instalada, às expansões a serem realizadas, às novas tecnologias a serem integradas à tecnologia já implantada e ainda a subsídios que sustentem investimento em tecnologia e em expansões;

ii. Engenharia e projetos: estas capacidades dizem respeito tanto à elaboração e implementação de projetos em rede celular como a projetos de estações rádio base, centrais de comutação e controle e redes de transmissão de dados.

\subsection{Capacidades tecnológicas em serviços}

Essa função tecnológica diz respeito a capacidades ligadas ao serviço prestado pela empresa por meio de sua rede celular, envolvendo todos os seus componentes (estações rádio base, centrais de comutação e controle, rede de transmissão de dados e pontos de interconexão). Nelas, encontram-se capacidades ligadas à qualidade e à inovação dos serviços prestados.

\subsection{Capacidades tecnológicas em equipamentos}

Essas capacidades dizem respeito à forma de operação e manutenção dos equipamentos da empresa ligados à prestação do serviço móvel celular. Também envolve capacidades ligadas à capacidade de fazer alterações nas configurações iniciais de rede, possibilitando adaptações às condições exigidas por seu mercado. 
Tabela 3. Métrica para capacidades tecnológicas em empresas prestadoras de serviço móvel celular

\begin{tabular}{|c|c|c|c|c|}
\hline \multirow{4}{*}{$\begin{array}{l}\text { Níveis de } \\
\text { capacidades } \\
\text { tecnológicas }\end{array}$} & \multicolumn{4}{|c|}{$\begin{array}{l}\text { FUNÇÕES TECNOLÓGICAS E ATIVIDADES RELACIONADAS } \\
\end{array}$} \\
\hline & \multicolumn{2}{|c|}{ GESTĀO DE PROJETOS } & \multirow{2}{*}{ SERVIÇOS } & \multirow{2}{*}{ EQUIPAMENTOS } \\
\hline & $\begin{array}{l}\text { DECISÃO E CONTROLE SOBRE A } \\
\text { PLANTA }\end{array}$ & ENGENHARIA E PROJETOS & & \\
\hline & \multicolumn{4}{|c|}{ ROTINA } \\
\hline BASICO & $\begin{array}{l}\text { Decisão sobre localização de CCCs e } \\
\text { pontos de interconexão }\end{array}$ & $\begin{array}{l}\text { Preparação inicial para implementação } \\
\text { de ERBs. Sincronização de trabalhos de } \\
\text { construção civil e instalação de } \\
\text { equipamentos de RFe TX }\end{array}$ & $\begin{array}{l}\text { Garantia do serviço básico prestado } \\
\text { dentro dos padrões mínimos de } \\
\text { qualidade. }\end{array}$ & $\begin{array}{l}\text { Configuração básica de equipamentos de ERB's. } \\
\text { Execução de tarefas básicas na central. } \\
\text { Manutenção corretiva em ERBs assistida pelo } \\
\text { fabricante. }\end{array}$ \\
\hline $\begin{array}{c}\text { (2) } \\
\text { RENOVADO }\end{array}$ & $\begin{array}{l}\text { Coleta e avaliação de medidas } \\
\text { operacionais e logs ligados à rede celular, } \\
\text { gerados pelas CCCs }\end{array}$ & $\begin{array}{l}\text { Serviços rotineiros de medidas de RF } \\
\text { em campo. Pequenas otimizações da } \\
\text { rede celular. }\end{array}$ & $\begin{array}{l}\text { Ajuste de parâmetros de serviços das } \\
\text { centrais assistida pelo fabricante. }\end{array}$ & $\begin{array}{l}\text { Acompanhamento de manutenções corretivas nas } \\
\text { CCCs. Execução de manutenções preventivas em } \\
\text { ERB's segundo procedimentos definidos pelo } \\
\text { fabricante. Trocas de softwares em ERBs. }\end{array}$ \\
\hline \multirow[b]{2}{*}{$\begin{array}{c}(3) \\
\text { EXTRA-BASICO }\end{array}$} & \multirow[b]{2}{*}{$\begin{array}{l}\text { Envolvimento em fontes de } \\
\text { financiamento para expansão da rede } \\
\text { celular. Envolvimento na definição de } \\
\text { plataformas básicas de valor agregado. }\end{array}$} & \multirow[b]{2}{*}{$\begin{array}{l}\text { Projeto e execução de enlaces de TX, } \\
\text { repetidores e ERBs em cidades do } \\
\text { interior. }\end{array}$} & \multicolumn{2}{|c|}{\begin{tabular}{|l|l|} 
INOVADORAS \\
\end{tabular}} \\
\hline & & & $\begin{array}{l}\text { Ajuste de parâmetros de serviço de a } \\
\text { partir de definições próprias para } \\
\text { atender ao mercado. Desenvolvimento } \\
\text { de novos serviços utilizando } \\
\text { plataformas já instaladas. }\end{array}$ & $\begin{array}{l}\text { Pequenas adaptações em ERB's para ajustá-las às } \\
\text { necessidades dos mercados.Definição de testes } \\
\text { automáticos em periféricos. } \\
\text { Definição de rotinas de manutenção preventiva em } \\
\text { ERB's. Execução de manutenções preventivas em } \\
\text { CCCs. }\end{array}$ \\
\hline $\begin{array}{c}\text { (4) } \\
\text { PRE- } \\
\text { INTERMEDIARIO }\end{array}$ & $\begin{array}{l}\text { Acompanhamento ativo de estudos de } \\
\text { viabilidade: de expansões de central; d } \\
\text { novas plataformas de serviços agregados. }\end{array}$ & $\begin{array}{l}\text { Engenharia e projetos de infra-estrutura, } \\
\text { em ERBs e CCC's. } \\
\text { Projeto e execução próprios de } \\
\text { pequenas expansões seguidas de } \\
\text { otimizações da rede celular. } \\
\text { Especificação de necessidades de } \\
\text { expansão de central } \\
\end{array}$ & $\begin{array}{l}\text { Aprimoramentos sistemáticos de } \\
\text { serviços básicos atingindo níveis } \\
\text { internacionais de qualidade. } \\
\text { Desenvolvimento conjunto com } \\
\text { fabricantes de novos serviços. } \\
\text { Aprimoramento contínuo de novos } \\
\text { serviços. }\end{array}$ & $\begin{array}{l}\text { Desenvolvimento de novas configurações para } \\
\text { estações. Desenvolvimento de novas aplicações em } \\
\text { periféricos na central. Troca de placas e cargas de } \\
\text { software dos módulos mais internos à central. } \\
\text { Definição de rotinas de manutenção preventiva em } \\
\text { CCCs. }\end{array}$ \\
\hline$\overline{(5)}$ & \multirow{2}{*}{$\begin{array}{l}\text { Gestão de: estudos de viabilidade, busca, } \\
\text { avaliação, seleção de fontes } \\
\text { financiamento. Desenvolvimento de } \\
\text { ferramentas para acompanhamento de } \\
\text { crescimento da rede celular }\end{array}$} & \multirow{2}{*}{$\begin{array}{l}\text { Projeto de grandes sistemas e/ou } \\
\text { expansões na rede celular/transmissão } \\
\text { sem assistência técnica. Projeto } \\
\text { assistido de expansões para CCCs }\end{array}$} & \multirow{2}{*}{$\begin{array}{l}\text { Desenvolvimento de novos serviços } \\
\text { sem auxílio de fabricantes. } \\
\text { Integração entre serviços já existentes. }\end{array}$} & \multirow{2}{*}{$\begin{array}{l}\text { Aplicação de novas versões de softwares das } \\
\text { centrais assistido pelo fabricante. } \\
\text { Desenvolvimento de novos sistemas integrados à } \\
\text { central. Desenvolvimento conjunto c/ fabricantes de } \\
\text { equipamentos para aumento da área de cobertura. }\end{array}$} \\
\hline INTERMEDIARIO & & & & \\
\hline (6) & \multirow{2}{*}{$\begin{array}{l}\text { Elaboração e implementação próprias de } \\
\text { projetos completos de expansão de CCCs. } \\
\text { Provisão de assistência técnica em } \\
\text { decisões de investimentos. }\end{array}$} & \multirow{2}{*}{$\begin{array}{l}\text { Integração de equipamentos de } \\
\text { tecnologias diferentes. Projeto e } \\
\text { implementação de novas facilidades de } \\
\text { software nas CCCs. }\end{array}$} & \multirow{2}{*}{$\begin{array}{l}\text { Desenvolvimento de serviços de alto } \\
\text { valor agregado. Customização de } \\
\text { pacotes de serviços especiais para } \\
\text { usuários específicos. }\end{array}$} & \multirow{2}{*}{$\begin{array}{l}\text { Implementação de novas tecnologias utilizando } \\
\text { novas facilidades de software e/ou periféricos. } \\
\text { Configuração da central para prestação de novos } \\
\text { serviços. }\end{array}$} \\
\hline $\begin{array}{l}\text { INTERMEDIARIO } \\
\text { SUPERIOR }\end{array}$ & & & & \\
\hline $\begin{array}{c}\text { (7) } \\
\text { AVANÇADO }\end{array}$ & $\begin{array}{l}\text { Gestão de projetos de novas centrais. } \\
\text { Desenvolvimento de novos sistemas de } \\
\text { comutação via P\&D. Desenvolvimento de } \\
\text { modelos de predição de evolução de redes } \\
\text { celulares. }\end{array}$ & $\begin{array}{l}\text { Implantação de redes de novas } \\
\text { tecnologias desenvolvidas via P\&D e } \\
\text { Engenharia. }\end{array}$ & $\begin{array}{l}\text { Desenvolvimento de serviços para } \\
\text { tecnologias de novas gerações. } \\
\text { Criação de serviços inéditos. } \\
\text { Desenvolvimento de novas plataformas } \\
\text { de serviço agregado via P\&D e } \\
\text { Engenharia. }\end{array}$ & $\begin{array}{l}\text { Desenvolvimento / implantação de sistemas de } \\
\text { software e hardware de nova geração segundo } \\
\text { padrões internacionais }\end{array}$ \\
\hline
\end{tabular}

Fonte: Adaptada de Figueiredo (2001) e validada por especialistas da indústria de telefonia móvel. 


\section{Desenho e métodos de estudo}

O estudo subjacente a este artigo foi estruturado para examinar as seguintes questões: (i) a dinâmica de acúmulo de capacidades tecnológicas nas duas empresas de telefonia móvel desde a sua criação até 2000; (ii) as implicações da acumulação de capacidades tecnológicas para a performance técnica. Para examinar estas questões com adequado nível de detalhe e profundidade, foi necessária a coleta de evidências primárias, qualitativas e quantitativas, sobre as atividades tecnológicas e os diversos indicadores de performance técnica. Essas evidências foram obtidas a partir de várias fontes: entrevistas com gerentes, engenheiros e técnicos, consultas a documentos (relatórios, padrões, dados históricos etc.) e observações diretas. Utilizou-se o método de estudo de caso comparativo (YIN, 2001) e as duas empresas foram selecionadas de maneira intencional (PATTON, 1990). Essa estratégia permitiu o exame desse tema com adequado nível de profundidade e de detalhe. Logo, este estudo pretende contribuir para o aprofundamento do entendimento da relação entre as questões centrais apresentadas, ou seja, pretende-se aqui fazer uma generalização analítica. A adaptação da métrica na Tabela 3 foi feita baseada em entrevistas com especialistas da indústria de telefonia celular

\section{Acumulação de capacidades tecnológicas nas empresas estudadas}

À luz da métrica na Tabela 3, nas seções seguintes são comparadas as trajetórias de acumulação de capacidades da Empresa X e da Empresa Y. A Seção 5.1 compara as trajetórias de acumulação de capacidades para a função gestão de projetos. A Seção 5.2, para a função serviços, enquanto que a Seção 5.3 a de equipamentos. De maneira geral, as evidências mostram que Empresa $Y$, ainda que mais jovem, acumulou capacidades muito mais rapidamente que a Empresa $X$. Não obstante, para as funções serviços e equipamentos, apesar de ter apresentado um processo mais lento, a Empresa $\mathrm{X}$ acumulou níveis mais elevados de capacidades do que a Empresa Y.

\subsection{Acumulação de capacidades para gestão de projetos}

As evidências colhidas em campo sugerem que a Empresa $X$ avançou em seu processo de acumulação de capacidades até o nível 6 (intermediário superior) na função decisão e controle sobre a planta. A Figura 2 indica que o processo de acumulação da Empresa $\mathrm{X}$ foi consideravelmente mais lento que o da Empresa $\mathrm{Y}$. Como operava em regime de monopólio, a empresa não precisava ajustar-se ao mercado. $\mathrm{O}$ mercado cresceria o quanto a operadora oferecesse como expansão. Adicionalmente, os pontos de interconexão de rede estariam dentro dela, o que dispensava a necessidade de definições ou planejamento prévios. Esses fatores citados (inerentes ao cenário no qual a Empresa $\mathrm{X}$ estava inserida) podem ter contribuído para que o processo de acumulação de capacidades para decisão e controle sobre a planta fosse mais lento do que o da Empresa Y.

Já no caso da Empresa Y, como apresentado na Seção 2, o cenário era distinto: uma empresa de capital privado que estava entrando em um mercado que até então era monopolista. Essas condições submetiam a Empresa Y a uma situação mais desafiadora que a obrigava a dar respostas rápidas aos problemas encontrados independente de sua origem. Sob essas circunstâncias, seu processo de acumulação foi consideravelmente mais veloz que o da Empresa X. Em praticamente dois anos de existência, a empresa igualou seu nível de acumulação ao da Empresa X para a função de decisão e controle sobre a planta, como pode ser constatado a partir da Figura 2 a seguir. 
Figura 2. Acumulação de capacidade tecnológica para decisão e controle sobre a planta na Empresa X (1993

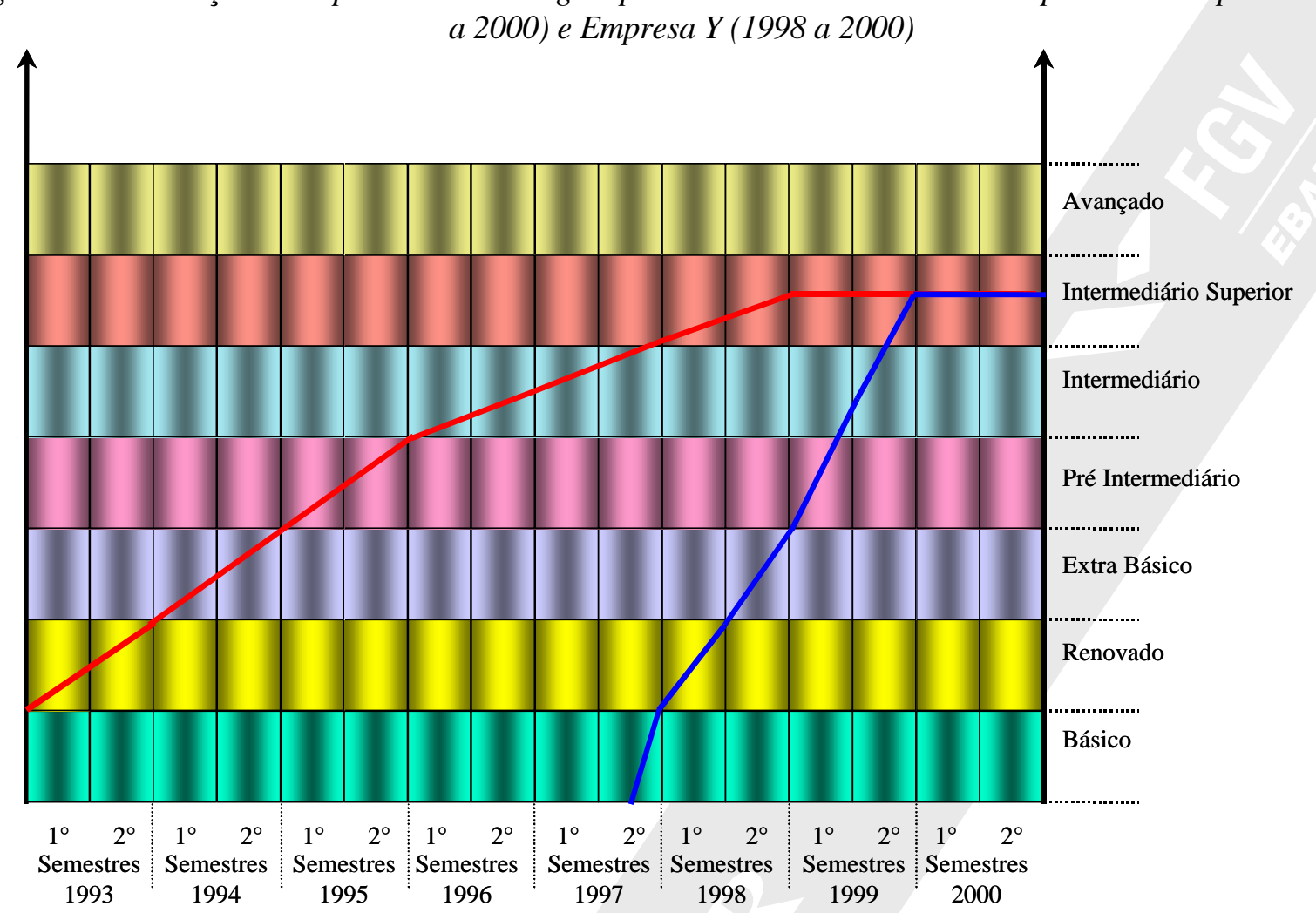

Empresa Y

\section{Empresa X}

Fonte: Derivado do estudo

De forma análoga, as trajetórias das duas empresas em termos de acumulação de capacidade tecnológica para engenharia e projetos são apresentadas na Figura 3. Chama a atenção o fato de a Empresa X ter alcançado nível 6 (intermediário superior) de capacidade para esta função tecnológica, o que não ocorreu integralmente com a Empresa Y. Relativamente, no entanto, a Empresa X apresenta uma trajetória de acumulação mais lenta que a da Empresa Y. 
Figura 3. Trajetória de acumulação da função tecnológica engenharia e projetos na Empresa X (1993 a 2000) e Empresa Y (1998 a 2000)

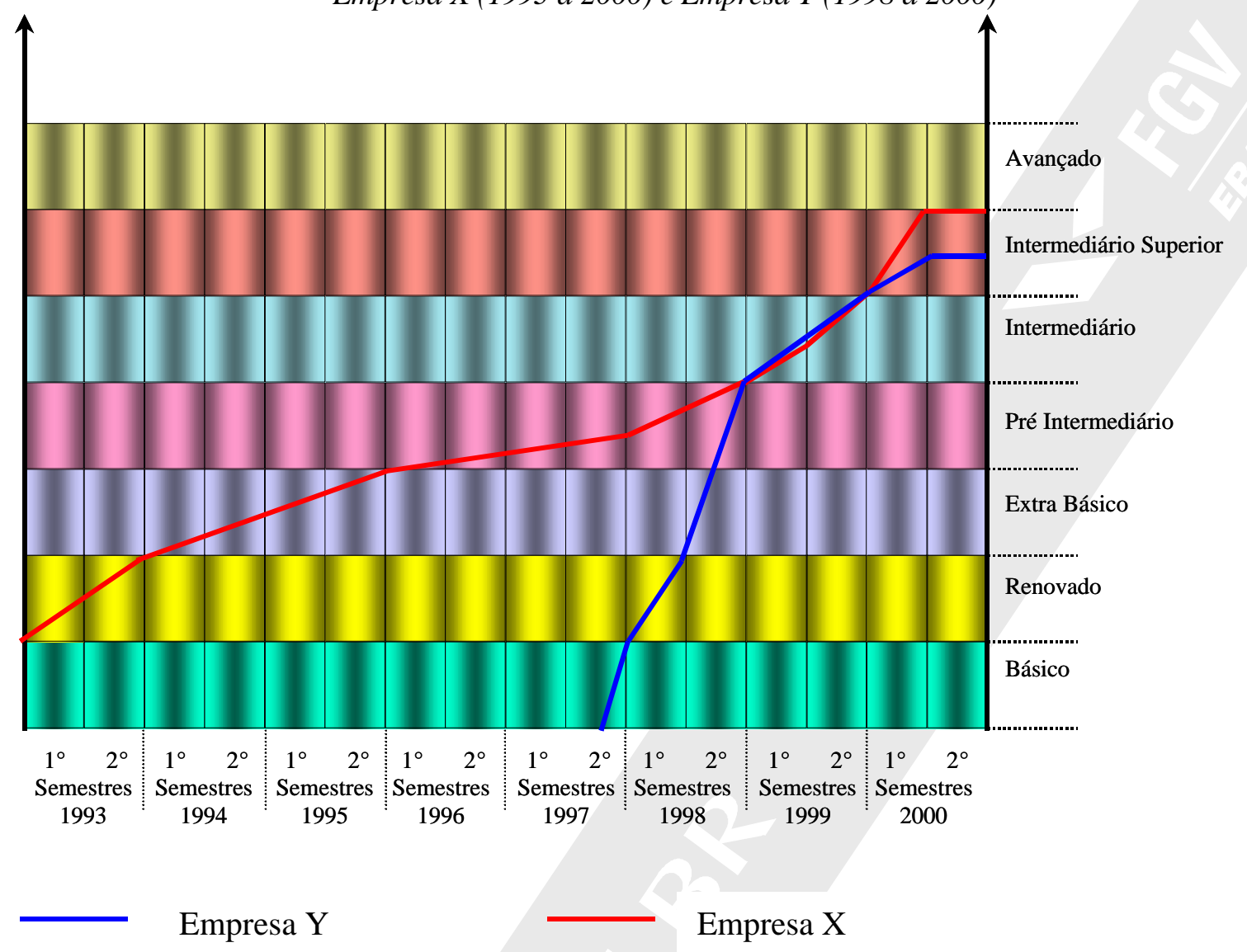

Fonte: Derivado do estudo

Com base na Figura 3 fica evidente que, a partir do primeiro semestre de 1998, a trajetória de acumulação tecnológica da Empresa $X$ acelerou-se consideravelmente. Nesse momento, a empresa passou a desenvolver e a executar novos projetos e ainda a adequar a sua rede às necessidades de crescimento e qualidade exigidas pelo mercado. Sob esse cenário, ela teve de aprimorar suas capacidades nessa função tecnológica, o que provavelmente obrigou-a a desenvolver capacidades de níveis superiores em engenharia e projeto.

De modo similar à função decisão e controle sobre a planta, nesta função de engenharia de projetos a Empresa Y seguiu uma trajetória de acumulação mais veloz que a da Empresa X. Com pouco mais de um ano de existência, a Empresa Y alcançou o mesmo nível de acumulação que a Empresa X. No entanto, ao final do ano 2000, a Empresa $X$ avançou mais no processo de acumulação de capacidades em engenharia e projetos alcançando o nível 6 - do que a Empresa Y, que acumulou esse nível apenas parcialmente.

Em resumo, a Empresa Y, na maior parte do período examinado, apresentou trajetórias de acumulação de capacidades consideravelmente mais aceleradas que as da Empresa X. No entanto, de maneira geral, esta última foi capaz de se igualar ou mesmo ultrapassar a Empresa Y quanto ao nível de capacidades acumulado, como foi o caso da função tecnológica engenharia e projetos.

\section{Acumulação de capacidades em serviços}

Como o ocorrido com a função tecnológica examinada na Seção 5.1, a trajetória de acumulação de capacidades da Empresa Y foi consideravelmente mais veloz que a da Empresa X. No entanto, após a privatização (meados de 1998), a Empresa X também passou a seguir uma trajetória de acumulação veloz, alcançando, ao final de 
2000 o Nível 6 de acumulação, ao passo que a Empresa Y, no mesmo ano, acumulou apenas até o Nível 5 (ver Figura 4 abaixo).

Figura 4. Acumulação de capacidade tecnológica para a função serviços na

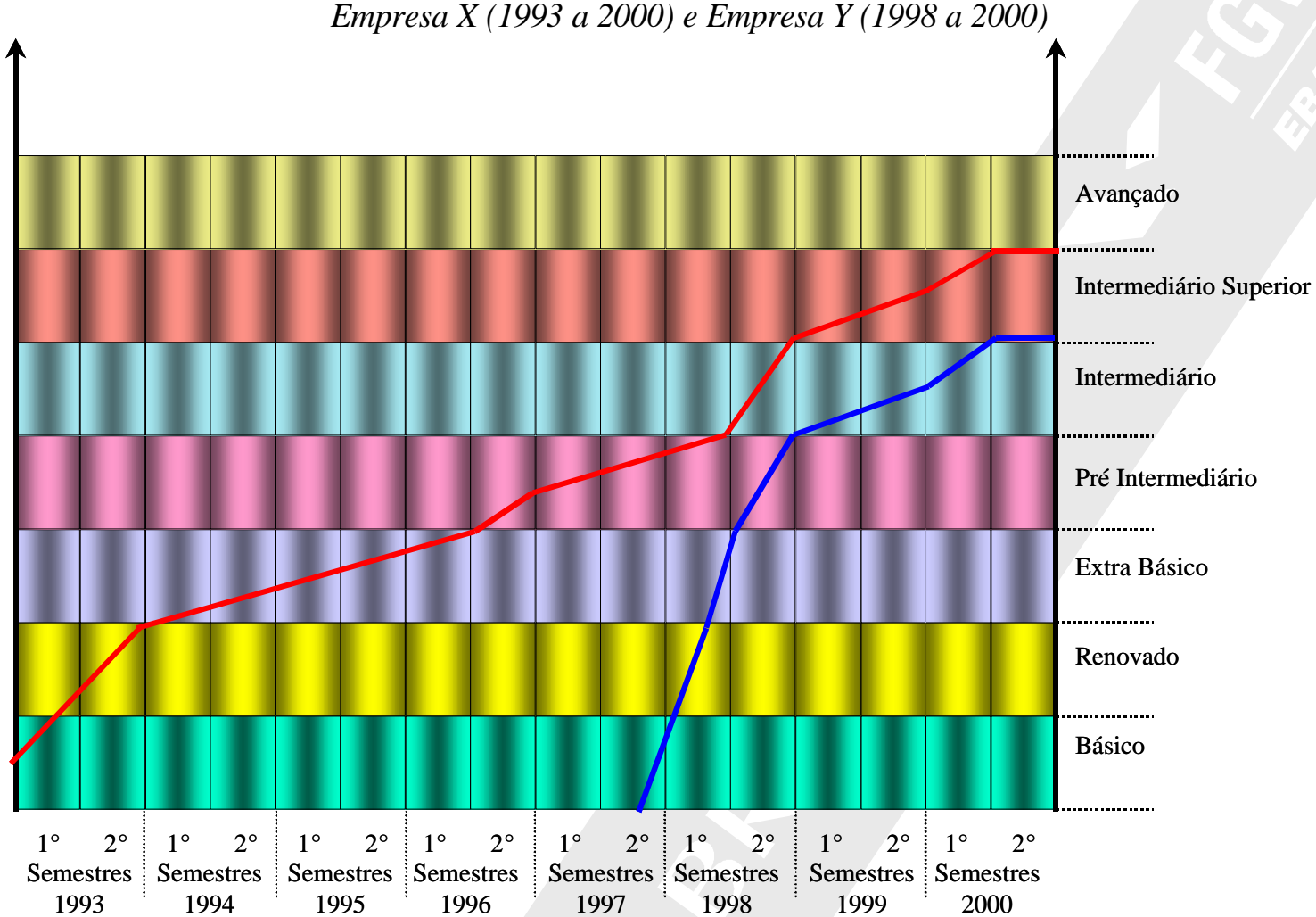

\section{Empresa Y}

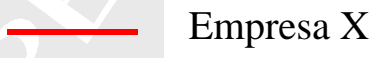

Fonte: Derivado do estudo.

\subsection{Acumulação de capacidades para atividades relacionadas a equipamentos}

Observando a Figura 5, pode-se constatar que, para as duas empresas, as trajetórias de acumulação da capacidade equipamentos apresentaram ritmos constantes de evolução. Como observado para as funções tecnológicas anteriores, para a função equipamentos, a Empresa Y também apresentou uma evolução mais rápida de sua trajetória de acumulação do que a Empresa X (ver Figura 5). Um fator que pode ter retardado o desenvolvimento dessa capacidade na Empresa X, foi o constante acompanhamento da Nortel/Promon na manutenção da rede. 
Figura 5. Trajetórias de acumulação da função tecnológica equipamentos para Empresa X (1993 a 2000) e

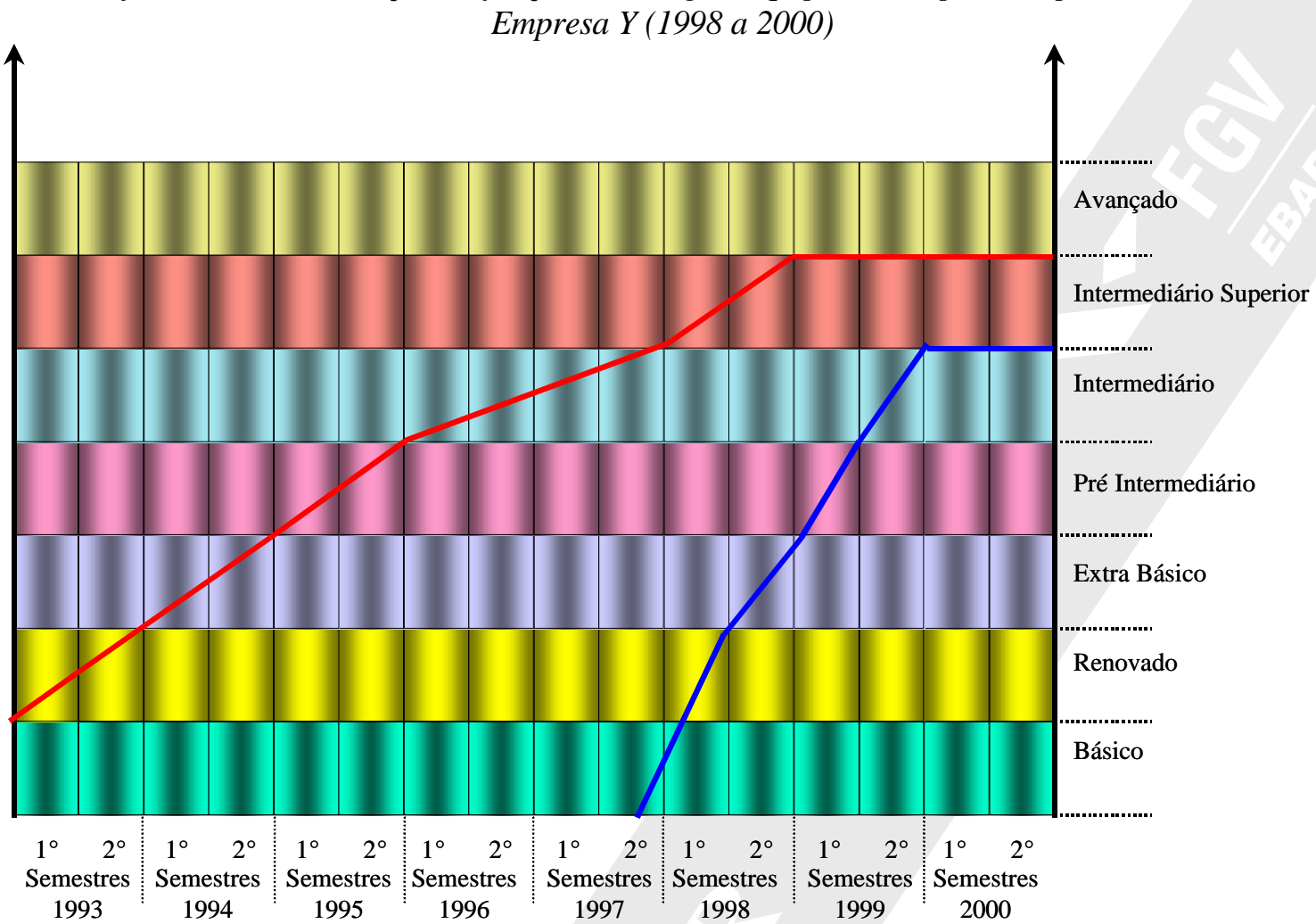

Empresa Y

Empresa X

Fonte: Derivado do estudo

Em resumo, pelo apresentado acima, para as quatro funções tecnológicas examinadas, a Empresa Y sempre apresentou trajetórias de acumulação que evoluíram consideravelmente mais rápido que as da Empresa $\mathrm{X}$. Em contrapartida, a Empresa X, em todas as funções tecnológicas estudadas, conseguiu acumular até o nível 6 de capacidades tecnológicas. O mesmo não ocorreu com a Empresa Y, que alcançou nível 6 somente para a função decisão e controle sobre a planta. Para as demais funções tecnológicas esse nível, em nenhum momento, chegou a ser totalmente acumulado. Ou seja, a Empresa $X$ acumulou em poucos anos os níveis de capacidade tecnológica que não tinha acumulado em sua existência. Essa aceleração em seu processo de acumulação tecnológica deu-se a partir da sua privatização e da pressão competitiva a partir de emergência de competidores como a Empresa Y. De outro lado, a capacidade de reação da Empresa X parece estar associada com suas capacidades tecnológicas prévias (ou latentes) que serviram de plataforma para esta reação tão rápida.

\section{Implicações da acumulação de capacidades tecnológicas para diferenças entre as duas empresas estudadas em termos de performance técnica}

Reconhecemos que performance técnica de empresas pode ser influenciada por vários fatores como, por exemplo, políticas governamentais de industrialização e incentivos à inovação tecnológica (DOSI, 1988; BELL \& PAVITT, 1993). Adicionalmente, a performance técnica de empresas pode ser indiretamente influenciada por processos subjacentes de aprendizagem que permitem às empresas a acumularem capacidades tecnológicas (FIGUEIREDO, 2001). Porém, tais questões, embora altamente relevantes, estão fora do seu escopo. 
Neste artigo, a performance técnica das duas empresas é examinada com base em indicadores típicos de rede de telefonia celular. Os indicadores utilizados para análise estão organizados em dois grupos: (i) indicadores que refletem a performance da rede quanto a parâmetros ligados à interface de rádio frequiência da rede, ou seja, ao meio que liga o usuário ao sistema; e (ii) indicadores relacionados à manutenção dos sistemas que compõem a rede celular. Os indicadores são apresentados na Tabela 4, a seguir.

Tabela 4. Indicadores de performance técnica estudados

\begin{tabular}{clc}
\hline \multicolumn{4}{c}{ Indicador } & \multicolumn{1}{c}{ Unidade } \\
\hline \multicolumn{3}{c}{ Grupo 1: Indicadores ligados à interface de RF } \\
\hline $\mathbf{1}$ & Taxa de queda de chamada & $\%$ \\
\hline $\mathbf{2}$ & $\begin{array}{l}\text { Razão de estações rádio base com queda de } \\
\text { chamada acima de 2\% }\end{array}$ & $\%$ \\
\hline $\mathbf{3}$ & Taxa de bloqueio de chamadas & $\%$ \\
\hline $\mathbf{4}$ & $\begin{array}{l}\text { Razão de estações rádio base com bloqueio } \\
\text { de chamada acima de 2\% }\end{array}$ & $\%$ \\
\hline $\mathbf{5}$ & Taxa de estabelecimento de chamada & $\%$ \\
\hline \multicolumn{3}{|c}{ Grupo 2: Indicadores ligados à manutenção do sistema } \\
\hline $\mathbf{6}$ & Taxa de disponibilidade de centrais & $\%$ \\
\hline $\mathbf{8}$ & Taxa de completamento de chamadas & $\%$ \\
\hline $\mathbf{9}$ & $\begin{array}{l}\text { Taxa de disponibilidade de estações rádio- } \\
\text { base }\end{array}$ & $\%$ \\
\hline $\mathbf{1 0}$ & Razão de estações com disponibilidade & $\%$ \\
\hline & Taxa de disponibilidade de serviço & $\%$ \\
\hline
\end{tabular}

\subsection{Implicações da acumulação de capacidades tecnológicas para diferenças entre as duas empresas -}

\section{indicadores do Grupo 1}

Nesta seção examinamos as implicações da acumulação de capacidades tecnológicas para as diferenças de performance técnica entre as empresas. Todas as atividades associadas a esse grupo de indicadores estão relacionadas à performance da interface de RF e à ampliação da rede celular. O seu desenvolvimento permite a adequação da rede celular às demandas de qualidade e de crescimento de tráfego, à medida que o número de usuários cresce.

No período de 1996 a 2000, a Empresa X apresentou uma significativa melhora na performance técnica de sua rede, principalmente nos dois últimos anos do período (1999 e 2000). Por exemplo, a média do indicador de queda de chamadas, no período entre 1993 e 1996 apresentava-se oscilando entre 5\% e 8\% (condições muito piores que a meta internacional de 2\%). Somente a partir de 1997, esse indicador passou a apresentar uma melhoria contínua em sua performance. Nesse mesmo período em que a Empresa X passa a executar atividades de expansão e otimização de sua rede celular (capacidade de nível 4 em gestão de projetos).

Tais atividades foram fundamentais para a melhoria das condições de interferência e de mobilidade na rede, pontos críticos para o indicador de queda de chamada. Aliadas a estas atividades, outras como execução de manutenções preventivas em estações rádio base (que passaram a ser executadas a partir de meados de 1998), ajustes de parâmetros de serviço associados à interface de RF e desenvolvimento de configurações de estações rádio base, também contribuíram para a melhoria desse indicador. No entanto, somente em meados de 1999, a Empresa $\mathrm{X}$ iniciou um grande projeto de expansão e de otimização de toda a sua rede (capacidade em nível 5 em gestão de projetos). Com essa implementação a empresa conseguiu adequar sua rede e ter condições para melhoras os ajustes de seus parâmetros de RF, o que possibilitou que, a partir de meados de 2000, o indicador de queda de chamada atingisse a meta internacional de $2 \%$. A Tabela 5 apresenta a evolução desse indicador nas duas empresas. 
Tabela 5. Queda de chamada na Empresa X (1996 a 2000) $e$ Empresa Y (1998 a 2000)

\begin{tabular}{ccc}
\hline Ano & $\begin{array}{c}\text { Empresa } \boldsymbol{X} \\
(\boldsymbol{\%})\end{array}$ & $\begin{array}{c}\text { Empresa } \boldsymbol{Y} \\
(\boldsymbol{\%})\end{array}$ \\
\hline $\mathbf{1 9 9 6}$ & 5.47 & - \\
\hline $\mathbf{1 9 9 7}$ & 4.26 & - \\
\hline $\mathbf{1 9 9 8}$ & 3.55 & 1.01 \\
\hline $\mathbf{1 9 9 9}$ & 2.92 & 1.14 \\
\hline $\mathbf{2 0 0 0}$ & 2.09 & 1.03 \\
\hline $\begin{array}{c}\text { Taxa média anual de } \\
\text { redução }(\%)\end{array}$ & -21.37 & 0.98 \\
\hline
\end{tabular}

Nota: Meta internacional: $<2 \%$

Fonte: Relatórios gerenciais da Empresa X e Empresa Y

Outro indicador desse grupo é o de bloqueio de chamadas, cuja evolução é mostrada na Tabela 6. Somente após início de 1997, esse indicador passou a apresentar condições significativas de aprimoramento de performance. Algumas atividades contribuíram para esse aprimoramento, tais como execução de expansões de centrais e de rede celular, atividades que começaram a ser desenvolvidas no início de 1996 (capacidade em nível 5 em gestão de projetos), desenvolvimento de novas configurações de estações rádio base dando-lhes maior capacidade de tráfego (capacidade em Nível 4 para atividades de equipamentos). Além dessas atividades, sem dúvida a mais importante foi a de expansão da rede para comportar um milhão de usuários, iniciada no final de 1999 (capacidade de Nível 5 em investimentos). Já no início de 2000, sua rede já apresentava taxas de bloqueio de chamada dentro de padrões internacionais (2\% de bloqueio). Durante praticamente todo o ano de 2000, a Empresa X manteve esse padrão de serviço. Esses esforços de aprimoramento também refletiram-se no indicador de razão de estações rádio base com bloqueio superior a $2 \%$, que apresentou um considerável aprimoramento ao longo dos anos: taxa média anual de redução de $-26.12 \%$ de 1996 a 2000.

Tabela 6. Taxa de bloqueio de chamadas na Empresa X (1996 a 2000)

\begin{tabular}{ccc}
\multicolumn{3}{c}{ e Empresa Y $(1998$ a 2000) } \\
\hline Ano & Empresa X (\%) & Empresa Y (\%) \\
\hline $\mathbf{1 9 9 6}$ & 12.26 & - \\
\hline $\mathbf{1 9 9 7}$ & 7.07 & - \\
\hline $\mathbf{1 9 9 8}$ & 2.20 & 0.41 \\
\hline $\mathbf{1 9 9 9}$ & 1.63 & 0.07 \\
\hline $\mathbf{2 0 0 0}$ & 0.52 & 0.28 \\
\hline $\begin{array}{c}\text { Taxa média anual de } \\
\text { redução (\%) }\end{array}$ & -54.62 & -17.36 \\
\hline
\end{tabular}

Nota: Meta internacional: $<2 \%$

Fonte: Relatórios gerenciais da Empresa X e da Empresa $\mathrm{Y}$

Em suma, as evidências acima sugerem que as capacidades tecnológicas acumuladas, principalmente em gestão de projetos e em equipamentos, contribuíram substanticialmente para que a Empresa $\mathrm{X}$ pudesse aprimorar sua performance técnica nos indicadores do Grupo 1.

No caso da Empresa Y, grande parte dos indicadores sempre apresentou-se dentro de padrões internacionais. O tamanho da rede e seu pouco tempo de operação eram fatores que favoreciam a performance do sistema. No entanto, seu crescimento acelerado teria rapidamente degradado sua performance se não fosse a execução de atividades relativas a expansão e otimização de sua rede. A Empresa Y rapidamente iniciou a execução de atividades como desenvolvimento de novas configurações em estações rádio base, execução de rotinas de manutenção preventiva, coleta e avaliação de 'logs' e medidas operacionais da rede, além de ajustes de parâmetros de serviços em suas centrais. Essas atividades contribuíram para constante avaliação e manutenção dos elevados índices de desempenho de sua rede, principalmente no que tange aos indicadores relacionados a queda e a estabelecimento de chamadas. Outras atividades executadas como expansão de central e execução de 
expansões de rede contribuíram para a manutenção de excelentes índices de bloqueio e estabelecimento de chamadas, atividades que começaram a serem desenvolvidas já no início de 1999, com pouco mais de um ano de operação.

Assim, a Empresa Y seguiu uma acelerada trajetória de acumulação de capacidades para as quatro funções tecnológicas. Por isso, a empresa executou rapidamente uma série de atividades que a auxiliaram na manutenção dos elevados padrões de performance técnica apresentados no início de sua operação. Esses padrões de qualidade, para os indicadores do Grupo 1, sempre foram consideravelmente melhores que os apresentados pela Empresa X, principalmente no que diz respeito aos indicadores de queda e bloqueio de chamadas.

As evidências apresentadas acima sugerem que, tanto para a Empresa $\mathrm{X}$ quanto para a Empresa $\mathrm{Y}$, a acumulação de capacidades teve implicações positivas para a performance técnica, medida por meio dos indicadores do Grupo 1. E ainda, devido ao fato de a Empresa Y ter acumulado mais rapidamente diferentes tipos e níveis mais elevados de capacidades, foi capaz de manter níveis de performance técnica de rede superiores aos da Empresa X. Esta, por sua vez, esforçou-se (lançando mão de sua capacidade previamente acumulada) para reverter, ainda que tardiamente, as condições de baixa performance apresentada em sua rede. Em outras palavras, os casos estudados sugerem que, para indicadores do Grupo 1, quanto maior o nível de acumulação de capacidades tecnológicas melhor é sua performance técnica.

\subsection{Implicações da acumulação de capacidades tecnológicas para diferenças entre as duas empresas - indicadores do Grupo 2}

No caso da Empresa X, durante a maior parte do período estudado (1993 a 2000), sua performance técnica foi equiparada ao nível internacional. Para os indicadores em questão, a robustez de operação dos equipamentos utilizados é um importante fator a ser considerado. No entanto, outros pontos devem ser ressaltados. Por exemplo, observando o indicador de taxa de disponibilidade da rede da Empresa X, constata-se uma evolução positiva de sua performance. Esta evolução teve outro fator importante, a execução de atividades para a expansão da rede celular iniciada no final de 1999 - que contribuiu para o aumento da capacidade da rede e manutenções preventivas.

Na rede da Empresa X, a taxa de completamento de chamadas apresentou desempenho abaixo da meta de 57\%. No entanto, manteve-se em níveis constantes, próximos da meta (em média 54\%). Considerando o grande aumento do número de usuários e as condições externas que influenciam esse indicador (por exemplo, a taxa de completamento das redes fixa e de longa distância), a manutenção do indicador pode ser considerado um bom resultado, que foi atingido em função de medidas como, expansão da rede celular, modificação da rede de transmissão de dados entre estações rádio base e centrais (capacidade de nível 5 em investimentos) e execução de manutenções preventivas em centrais (capacidade de nível 4 em equipamentos). Portanto, as evidências sugerem que a acumulação de capacidade tecnológicas na Empresa $\mathrm{X}$ tenham contribuído para os bons resultados de performance apresentado pelos indicadores do Grupo 2.

Quanto à Empresa Y, aqui ocorre um fato análogo ao descrito para o Grupo 1 de indicadores. Ou seja, a execução de uma série de atividades que contribuíram positivamente para a boa performance de sua rede, mesmo sob circunstâncias desfavoráveis de uma expansão acelerada. A execução de atividades de manutenção preventiva em sua rede (estabelecidas desde meados de 1998), tais como alteração da configuração de estações rádio base, definição de testes automáticos preventivos nas estações, permitiram a manutenção de indicadores como disponibilidade de estações rádio base, razão de estações rádio base com disponibilidade inferior a $98.5 \%$, em níveis de performance internacional. Essas evidências novamente sugerem que a rápida acumulação de capacidades contribuiu para o aprimoramento da performance técnica da rede da Empresa Y. 


\section{Conclusões e implicações para gestão}

Este artigo examinou as implicações da acumulação de capacidades tecnológicas para o aprimoramento de performance técnica em duas empresas de telefonia celular no Brasil . O estudo adotou uma perspectiva abrangente para capacidade tecnológica. Essa perspectiva vai além dos seus elementos convencionais, tais como sistemas técnico-físicos e capital humano, e capta a dimensão organizacional e gerencial da capacidade tecnológica - elementos essenciais para a realização de inovação e para o aprimoramento de performance técnico-econômica. Por isso, neste estudo examinamos a atividade tecnológica - aquilo que a empresa sabe fazer tecnológicamente, de maneira independente - como expressão da capacidade tecnológica. Para operacionalizar tal perspectiva, fizemos uso de uma métrica sistemática, compreensiva e calibrada para a indústria de telefonia celular para examinar a acumulação de capacidades para quatro tipos de atividade: (i) decisão e controle sobre a planta; (ii) engenharia e projtos; (iii) serviços; e (iv) equipamentos. $\mathrm{O}$ artigo fez uso de vários indicadores de performance técnica, em nível das empresas estudadas.

\subsection{Em termos da acumulação de capacidades tecnológicas}

No início de suas operações, tanto a Empresa X quanto a Empresa Y careciam até mesmo de capacidades básicas para operarem suas redes celulares. No entanto, logo após a ativação de suas redes, essas empresas engajaram-se em processos de acumulação de capacidades tecnológicas. As evidências sugerem que a Empresa X passou por período de acumulação lenta de capacidades, quando parte de seus indicadores operacionais apresentou um baixo desempenho. Esse período pode ser delimitado cronologicamente a partir da criação da Empresa X (início de 1993), com a implantação inicial de sua rede celular, até a sua privatização (meados de 1998).

Durante esse período, a Empresa X era uma empresa estatal e detinha o monopólio do mercado, estando, portanto, em uma situação bastante confortável na indústria. Não importava a qualidade do serviço prestado; ele seria o único, e o usuário estaria obrigado a se submeter às condições existentes desse serviço. E ainda, a empresa não necessariamente precisava remunerar o governo, seu único acionista. Nesse contexto, a empresa não era estimulada apresentar bons índices de performance técnica ou mesmo capacitar-se para tanto. Nessas condições, a empresa apresentou um processo lento de acumulação de capacidades. Já no segundo período, houve uma mudança no cenário. A Empresa $X$ foi privatizada, precisaria remunerar sua acionista, tarefa que ficaria mais difícil diante de uma condição de concorrência de mercado. Nesse momento, a empresa necessariamente deveria apresentar melhores serviços, melhor qualidade de rede, dentre uma série de outros diferenciais de mercado, para ser capaz de fazer frente ao concorrente que acabava de iniciar suas operações. Ou seja, diante desse novo cenário, a Empresa $X$ foi obrigada a desenvolver rapidamente suas capacidades para aprimorar sua qualidade e seus serviços. A Empresa X passou a apresentar uma velocidade mais acentuada no processo de acumulação de capacidades para todas as funções tecnológicas estudadas, ultrapassando, para todas elas, o nível 5 em capacidade (nível 5 em investimentos; nível 6 em serviços e nível 6 em equipamentos).

Por outro lado, verifica-se que a Empresa Y, que sempre operou em um mercado de competição e foi exigida quanto aos seus resultados desde sua criação, apresentou uma velocidade acentuada em seu processo de acumulação de capacidades tecnológicas. Quando comparada com a Empresa X, a Empresa Y apresenta velocidades superiores de acumulação de capacidades. É importante notar que ela chegou a acumular nível 5 de capacidades em todas as funções tecnológicas estudadas, em apenas pouco mais de três anos de operação. Esses fatos sugerem que, em um ambiente de competição acirrada, onde a qualidade dos serviços é uma condição importante para sua permanência no mercado, as empresas sejam obrigadas a desenvolver capacidades a uma velocidade mais acentuada do que quando inseridas em um mercado protegido e cativo onde tal exigência não existe. Em suma, a partir dos estudos realizados alguns pontos podem ser ressaltados:

- A partir de sua privatização e com a entrada de um competidor em seu mercado, a Empresa X acelerou seu processo de acumulação de capacidades para todas as funções tecnológicas estudadas;

- A Empresa Y, que sempre esteve submetida a uma condição de competição de mercado apresentou, para as quatro funções tecnológicas examinadas, velocidades de acumulação de capacidades mais elevadas que a Empresa X; 


\subsection{Em termos das implicações da acumulação de capacidades tecnológicas para a performance técnica}

As evidências apresentadas sugerem que a acumulação de capacidades tecnológicas em gestão de projetos e em equipamentos foi fundamental para o aprimoramento da performance técnica nas duas empresas. Esta importância vem do fato de que essas capacidades estão associadas ao desenvolvimento de atividades diretamente ligadas à qualidade do sistema.

Neste sentido, a acumulação dessas capacidades permitiu à Empresa X a executar atividades de expansão e de otimização de rede celular de forma a adequar seu sistema às suas necessidades, próprias ao mercado mineiro. Essas atividades - que, no Brasil, eram em geral executadas pelos fornecedores, fabricantes dos equipamentos - permitiram que as novas expansões de rede feitas pela própria Empresa $\mathrm{X}$ fossem projetadas e implementadas atendendo às condições particulares de seu mercado e corrigindo problemas da concepção inicial do sistema. À medida que a rede foi sendo adequada, sua performance foi melhorando, chegando a apresentar índices internacionais. Fato análogo ocorreu com a Empresa Y. No entanto, como sua acumulação de capacidades foi mais rápida, ela pôde executar as referidas atividades desde o início de sua operação mantendo a performance de sua rede em níveis internacionais à medida que o sistema crescia.

Portanto, as evidências sugerem que a acumulação de capacidades em gestão de projetos e em equipamentos teve implicações positivas para a melhoria da performance técnica das redes celulares da empresas estudadas. Portanto, diferenças nas trajetórias de acumulação de capacidade tecnológica tiveram implicações positivas significativas para as duas empresas em termos de performance técnica. Este ponto alinha-se a estudos anteriores como, por exemplo, Penrose (1959), Hollander (1965), Dosi (1988) e Figueiredo (2001). No entanto, não foram encontradas evidências que indicassem implicações efetivas da acumulação de capacidades em serviços na performance técnica das empresas, o que pode estar relacionado com a definição de performance técnica. Nesse caso, se outros indicadores tivessem sido considerados, novas relações/implicações poderiam ter sido constatadas.

\subsection{Implicações para a gestão de empresas de telefonia celular}

As evidências colhidas ao longo do trabalho mostram o caráter estratégico da acumulação de capacidades em gestão de projetos e em equipamentos, que estão, como apresentado, associadas à qualidade da operação da rede. E ainda, os problemas de concepção no projeto das duas redes, tanto da Empresa X quanto da Empresa Y, indicam que em geral, os fabricantes de equipamentos não possuem capacidade adequada para projeto e implantação de redes. Dessa forma, torna-se fundamental para as operadoras acumularem rapidamente capacidades nessas funções tecnológicas a fim de garantirem, desde o início de suas atividades, a manutenção de um padrão de qualidade em suas redes.

Essa necessidade torna-se mais evidente quando o panorama do mercado de telecomunicações no Brasil é avaliado: um mercado ávido pela oferta de novas tecnologias e novos serviços. Nesse contexto, a qualidade de operação das redes será uma condição fundamental para o sucesso das empresas. E, por estarem associadas à manutenção dessa qualidade da rede, a acumulação (e sustentação) das capacidades tecnológicas, como essas examinadas aqui, torna-se um fator importante para o sucesso dessas empresas. Portanto, torna-se crucial aos gestores dessas empresas o desenvolvimento de esforços para o desenvolvimento de capacidades internas que permitam que suas equipes assumam mais rapidamente possível o controle das atividades de operação, de projeto e de otimização de suas redes. 


\section{Referências bibliográficas}

BELL, M. \& PAVITT, K. Tecnological acumulation and industrial growth: contrasts between developed and developing countries. Industrial and Corporate Change, v. 2, $n^{\circ} 2,1993$.

BELLINGHINI, M. F. \& FIGUEIREDO P. N. Capacidades tecnológicas e estratégia empresarial: evidências em nível de empresa da industria de telefonia fixa no Brasil. Revista de Administração Mackenzie, 2005. (forthcoming)

BEN, F. \& FIGUEIREDO P. N. Acumulação de Capacidades Tecnológicas na Indústria Moveleira: Implicações para Diferenças entre Empresas em Termos de Performance Técnico-Econômica. Cadernos EBAPE.BR, Edição Especial, 2005.

DAHLMAN, C. \& FONSECA F.V. From Technological Dependence to Technological Development: The Case of the USIMINAS Steel Plant in Brazil, Working Paper, no. 21, IBD/ECLA Research Programme, 1978.

DODGSON, M. Organisational Learning: a Review of Some Literatures. Organisation Studies, v. 14, no 3, 1993, pp. 376-94.

DOSI, G. The nature of the innovative process. In: DOSI, G., FREEMAN, C., NELSON, R., SILVERBERG, G. \& SOETE, L. (eds.). Technical change and economic theory. Londres: Pinter Publishers, 1988.

The Microeconomic Sources and Effects of Innovation. An Assessment of Some Recent Findings, DRC Discussion Paper, SPRU, Üniversity of Sussex, ำ 33, 1985.

FIGUEIREDO, P. N. Technological learning and competitive performance. Cheltenham, UK, \& Northampton, USA: Edward Elgar, 2001.

HOLLANDER, S. The Sources of Increased Efficiency: a Study of Du Pont Rayon Plants. Cambridge: MIT Press, 1965.

KATZ, J. Importación de Tecnologia, Aprendizage y Industrialización Dependiente, México: Fondo de Cultura Economica, 1976.

LEONARD-BARTON, D. Core Capabilities, Core Rigidities: Paradox in Managing New Product Development, Strategic Management Journal, V. 13, 1992, pp. 111- 125.

Wellsprings of Knowledge: Building and Sustaining the Sources of Innovation, Boston, MA: Harvard Business School Press, 1995.

MALERBA, F. \& ORSENIGO L. Technological Regimes and Organizational Behaviour. Industrial and Corporate Change, v. 2, no 1, 1993, pp. 45-71.

MARCH, J . \& SIMON H. Organizations, New York: Wiley, 1958.

NELSON, R. The Role of Firm Differences in a Evolutionary Theory of Technical Advance. Science and Public Policy, v. 18, no 6, 1991, pp. 347-52.

NELSON, R. \& WINTER, S. An evolutionary theory of economic change. Cambridge: Harvard University, 1982.

PACK, H. Productivity, Technology and Industrial Development. A Case Study in Textiles, New York: Oxford University Press, 1987.

PATTON, M. Q. Qualitative Evaluation and Research Methods, 2nd edn, Newbury Park, California: Sage, 1990.

PAVITT, K. Strategic Management in the Innovating Firm, DRC Discussion Paper, nํ. 61, SPRU, University of Sussex., 1988.

PAVITT, K. Key Characteristics of the Large Innovating Firm. British Journal of Management, v. 2, 1991, pp. 41-50.

PENROSE, E. T. Theory of the growth of the firm. Oxford, Basil, Blackwell, 1959.

PICCININI, M. Technical Change and Energy Efficiency: a Case Study in the Iron and Steel Industry in Brazil. D.Phil Thesis, SPRU, University of Sussex, 1993.

PRAHALAD, C. \& HAM EL G. The Core Competence of the Corporation. Harvard Business Review, v. 90, no 3, 1990, pp. 79-91.

ROSENBERG, N. Inside the Black-Box, Cambridge: Cambridge University Press, 1982.

SIMON, H. Theories of Decision Making in Economics and Behavioral Science. American Economic Review, v. 49, n- 3, 1959, pp. $253-83$.

SIM ON, H. Administrative Behaviour. A Study of Decision-Making Process in Administrative Organisation, 2nd edn, New York: Macmillan, 1961.

TEECE, D. J. Technological Change and the Nature of the Firm. In: DOSI, G. et al (eds), Technical change and economic theory. London, Pinter, 1988.

TEECE, D.; PISANO J. G. \& SHUEN, A. Firm capabilities, resources and the concept of strategy: four paradigms of strategic management. University of California at Berkeley, 1990.

TEECE, D. \& PISANO G. The Dynamic Capabilities of Firms: an Introduction. Industrial and Corporate Change, v. 3 no3, 1994, pp.537-56.

TREM BLAY, P. Comparative analysis of technological capability and productivity growth in industrialized/industrializing countries. DPhil Thesis. SPRU University of Sussex, Brighton, UK, 1994.

WINTER, S. On Coase, Competence, and the Corporation. Journal of Law,Economics, and Organisation, v. 4, no 1, 1988, pp.163-80.

YIN, R. Estudo de caso: Planejamento e Métodos. 2ª edição. Porto Alegre: Brookman, 2001. 